\title{
Development of a 3-D Printer Selection Engine
}

\section{Dr. Ranjeet Agarwala, East Carolina University}

Dr. Ranjeet Agarwala serves as an Assistant Professor in the Department of Technology Systems at East Carolina University. He holds a PhD in Mechanical Engineering from the North Carolina State University. Since 2001 he has taught courses in Engineering Design, Digital Manufacturing, and 3D printing, GD\&T, Electro-Mechanical Systems, Statics and Dynamics. His research interests are in the areas on Advance and Digital Manufacturing and its integration with the renewable energy sector.

\section{Dr. Robert A. Chin, East Carolina University}

Robert A. "Bob" Chin is a full professor in the Department of Technology Systems, College of Engineering and Technology, East Carolina University, where he has taught since 1986. He is the past director of publications for the Engineering Design Graphics Division and the past editor for the Engineering Design Graphics Journal. Chin has also served as the Engineering Design Graphics Division's annual and mid-year conference program chair, and he has served as a review board member for several journals including the EDGJ. He has been a program chair for the Southeastern Section and has served as the Engineering Design Graphics Division's vice chair and chair and as the Instructional Unit's secretary, vice chair, and chair. His ongoing involvement with ASEE focuses primarily on annual conference paper presentation themes associated with the Engineering Design Graphics, the Engineering Technology, and the New Engineering Educators Divisions and their education and instructional agendas.

\section{Mr. Daniel P. Zuberbier, East Carolina University}

Dan Zuberbier is the Education \& Instructional Technology Librarian at East Carolina University (ECU). He planned for, launched, and currently manages the J.Y. Joyner Library 3D printing service which makes 3D printing accessible to all students, faculty and staff at ECU, and is currently developing a course on 3D printing for the North Carolina Summer Ventures in Math \& Science Program. He previously worked as a high school Social Studies teacher in Arizona and Michigan, and holds an M.L.I.S. from the University of Wisconsin-Milwaukee. His professional interests include teachers' perceptions of school library programs and school librarians as a resource and assisting educators with integrating emerging technologies into the classroom.

\section{Prof. Mark McKinley Sanders, East Carolina University}

Mark Sanders is the Assistant Director for Public Services at East Carolina University's (ECU) Joyner Library. Previously he worked as a Reference and Outreach Librarian at ECU and Louisiana State University. He holds an M.S. in Library Science from UNC-Chapel Hill and an M.A. in Spanish literature from Penn State University. His professional interests include student centered learning spaces, innovative services, and new technologies. 


\title{
Development of a 3D Printer Selection Engine
}

\begin{abstract}
This paper focuses on the deployment of a tool that will enable any category of end user to match their needs and product specifications to 3D printers by means of a webpage. Any user connected to a network can enter the CAD geometry and product specifications into a web based form to select the most appropriate $3 \mathrm{D}$ printer. The parameters that drive the selection of $3 \mathrm{D}$ printers have been inspired by the largest/biggest/most well-known 3D printer manufacturers. The purpose of the selection system is to display printer specification in a common format so users are able to make "apples to apples" comparisons. The resource and the database will continuously expand and improve the 3D printing pairing engine. The technology, techniques and methods of designing the 3D printer selection engine is reported in this paper.
\end{abstract}

\section{Introduction}

3D printing is an integral part of the visualization, design, and prototyping process. As it becomes more accessible to even the layperson, it has spawned new industries and small businesses ${ }^{2,3,4,5}$. Friedman ${ }^{6}$ has suggested that technology_ie computers, modems, cell phones, cable systems, the Internet, and the like - have enabled us all to reach further into more and more countries and into one another's lives, faster, deeper, and cheaper than we've ever done before. Referring to this phenomenon as "the democratization of technology", this phenomenon, according Friedman, has put banks, offices, newspapers, bookstores, brokerage firms, schools, and even factories in our homes.3D printing has paved a path for the democratization of manufacturing and is perceived by some as the next industrial revolution ${ }^{7}$. It has created a paradigm shift in the practice and process of traditional manufacturing aided by the interconnectivity and digitization offered by information technology. It has become an integral part of the visualization, design, and prototyping process and in the production of goods.

As 3D Printing becomes more accessible aided by copious 3D printers being introduced the market every year, hobbyists, K12 schools, libraries, professionals and other end-users around the globe are facing increasing difficulties making educated decisions when selecting a 3D printer. Many 3D printer experts and scholars ${ }^{11,12,13,14,15}$ have studied and reported on strategies for selecting suitable 3D printers based on a given design. They have either limited their investigations to professional users or restricted their research to 3D printer parameters and part accuracies. Also, at any point in time, research is superseded as new and improved 3D printers are introduced to the market. On the other hand, many big 3D printer manufacturing companies such as 3D systems ${ }^{10}$, Stratasys ${ }^{8}$, and Makerbot ${ }^{9}$, provide their printer specifications in disparate format making an "apples to apples" comparisons difficult. As well, the layperson and even professionals may not have access to these resources or may have difficulty assimilating these through conference and journal papers. And in many instances, jargon and many terms may make no sense to the layperson.

The authors in their prior work ${ }^{1}$ have designed a system model and associated parameters for the design of a web based 3D printer selection system. This paper expands on their previous work and focuses on the deployment of a tool that will enable any category of end user to match their 
needs and product specifications to 3D printers by means of a webpage. The technology, techniques and methods of designing the $3 \mathrm{D}$ printer selection engine is reported in this paper.

\section{Model and Method}

Figure 1 depicts the webpage of the Selection Engine; Figure 2 depicts the high level model for the system. The webpage introduces the user to the selection engine. Links are provided to access resources such as selection engine, user feedback and to educate novice users about 3D printers and materials. Like a digital index, this resource enables any category of end user to match their product specification to 3D printers by means of a webpage mapped to a central 3D printer database. Any users connected to a network can enter the CAD geometry and product specifications into a web based form to enable selection of a 3D printer. The parameters that drive the selection of $3 \mathrm{D}$ printers have been reverse engineered from most common and widely used 3D printer specifications such as 3D Systems ${ }^{10}$, Stratasys ${ }^{11}$, and Makerbot ${ }^{12}$.

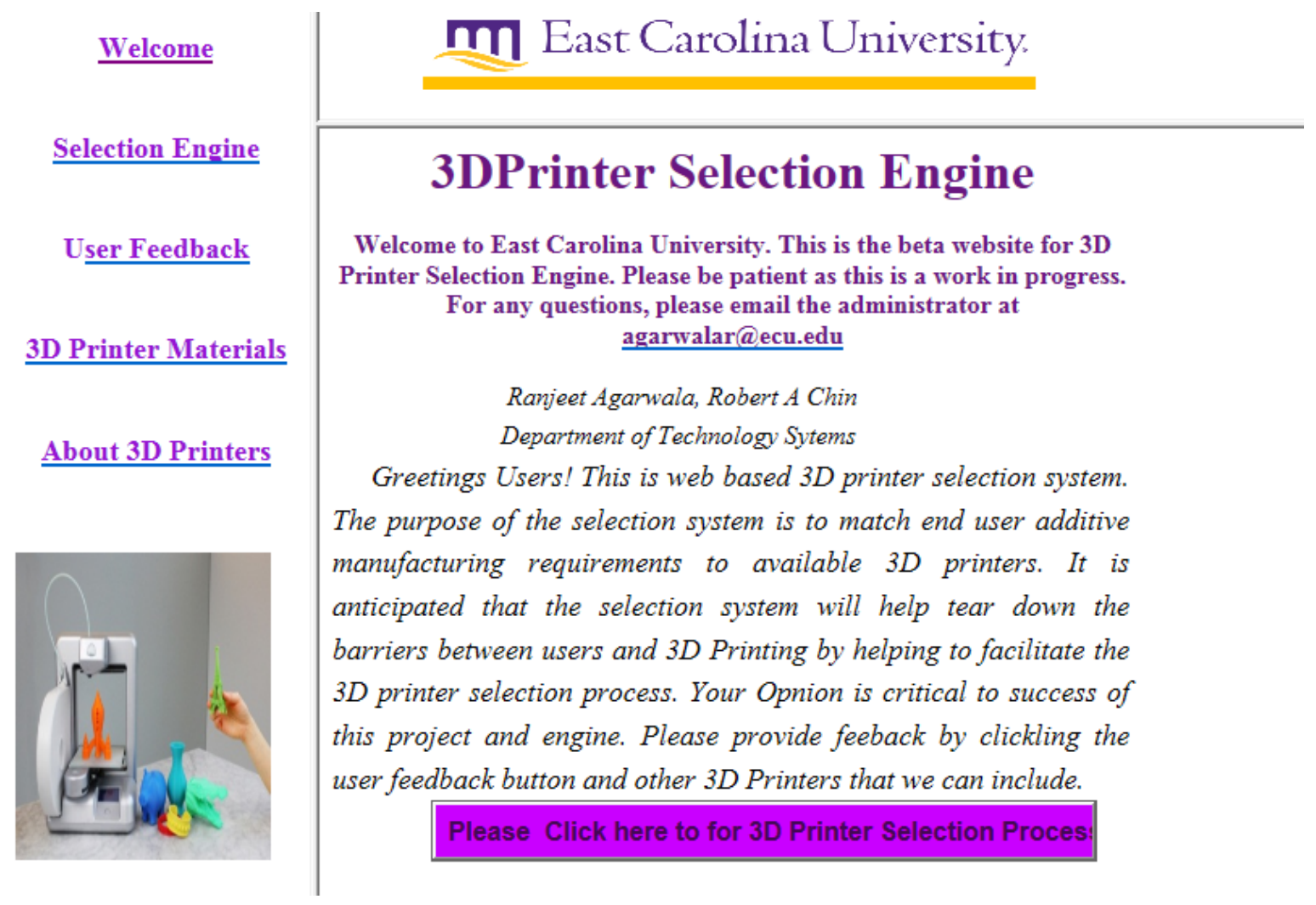

Figure 1. Webpage of the 3D Printer Selection Engine. 


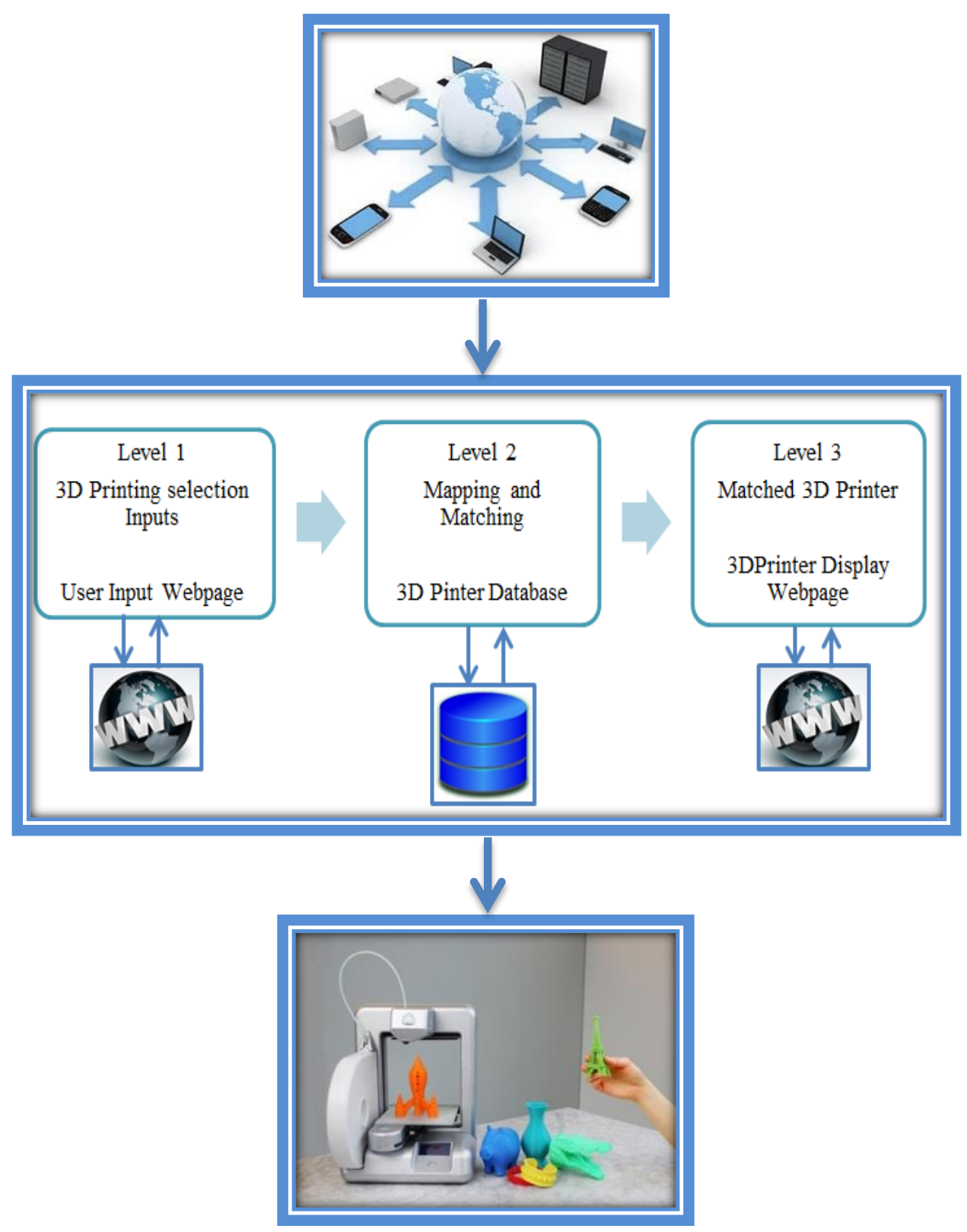

Figure 2. 3D Printer Selection System Model.

The system level model has been designed as an improvement over previous research to include a web based entry and display system making the selection system more accessible. Also the purpose of the selection system is to display printer specification in a common format for "apples to apples" comparison. Level 1 of the system is used by a user to enter user category and desired product specifications and submit them to the 3D printer server. System Level 2 converts the users' inputs into matching and mapping query to the database of $3 \mathrm{D}$ printers.

Once a suitable match has been found, a webpage containing suitable 3D printers will be displayed in Level 3 with a hyperlink to the machine webpage hosted on the manufacturer's website. As new 3D printers become available commercially, they will be added to the database. 
The authors and the graduate students dedicated to creating this database of 3D printers will continuously update the database as new 3D printers become available.

\section{D Printer Selection Engine}

The selection parameters of the web based 3D printer selection system are the product and design specifications such as model dimensions, material type and the category of users to name a few. Figure 3 depicts the user interface as being developed on Microsoft Expression Web 4.0 and being deployed on the local server. Figure 4 depicts the parameters of the system that the end user inputs at Level 1. These parameters that drive the selection of 3D printers have been reverse engineered from most common and widely used 3D printer specifications such as 3D Systems, Stratasys, and Makerbot.

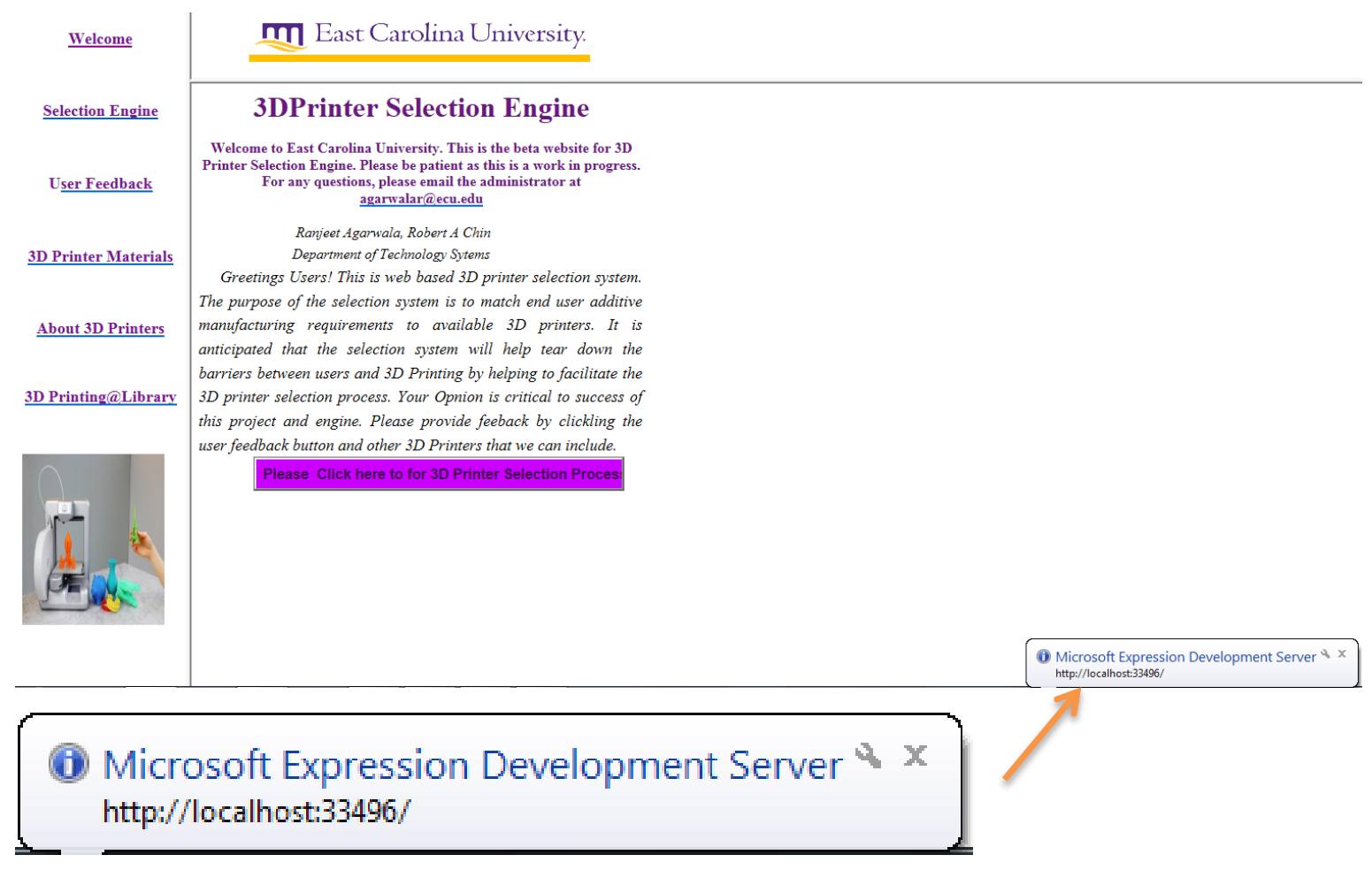

Figure 3. User and Server Interface.

Broadly these parameters are classified as category of user, the part dimensions of the product, the material of the product, different colors needed, the overall part costs, and the resolution of the desired product and is depicted in Figure 4. 


\begin{tabular}{|c|c|c|}
\hline Category of User (Please select only one choice)* & $\begin{array}{l}\text { Beginner } \\
\text { Designer } \\
\text { Professional } \\
\text { Medical/Dental }\end{array}$ & \\
\hline $\begin{array}{l}\text { Part Dimension-Length in inches } \\
\text { (Please select a range by using the drop down menu) }\end{array}$ & Minimum Lenght $1 \mathrm{~V}$ & Maximum Length $2 \checkmark$ \\
\hline $\begin{array}{l}\text { Part Dimension-Width inches) } \\
\text { (Please select a range by using the drop down menu) }\end{array}$ & Minimum Width $1 \checkmark$ & Maximum Width $2 \checkmark$ \\
\hline $\begin{array}{l}\text { Part Dimension-Height inches } \\
\text { Please select a range by using the drop down menu) }\end{array}$ & Minimum Height $1 \checkmark$ & Maximum Height $2 \vee$ \\
\hline $\begin{array}{l}\text { Available Material } \\
\text { Please Select from the drop down list) }\end{array}$ & ABS & \\
\hline $\begin{array}{l}\text { Do you want a Multi-Colored Part? } \\
\text { (Multi-colred part may cost more) }\end{array}$ & $\begin{array}{l}\text { OYes } \\
\bigcirc \text { No }\end{array}$ & \\
\hline $\begin{array}{l}\text { Part Cost (S)/cubic inch } \\
\text { Please select a range by using the drop down menu) }\end{array}$ & Minimum Cost $1 \mathrm{~V}$ & Maximum Cost $2 \checkmark$ \\
\hline $\begin{array}{l}\text { Part Resolution (Layer thickness in micron) } \\
\text { (Please select a range. Hint: } 1 \text { micron is one thousands of an inch) }\end{array}$ & High Resolution $1 \checkmark$ & Low Resolution $20 \mathrm{~V}$ \\
\hline
\end{tabular}

Figure 4. Selection Parameters.

A radio button is used to select the user type ranging from a Beginner to a Medical/Dental Professional. Two sets of three inputs are incorporated for entering the minimum and maximum part build volume indicating the min and max length, width, and height of the part as drop down menus as depicted in Figure 5.

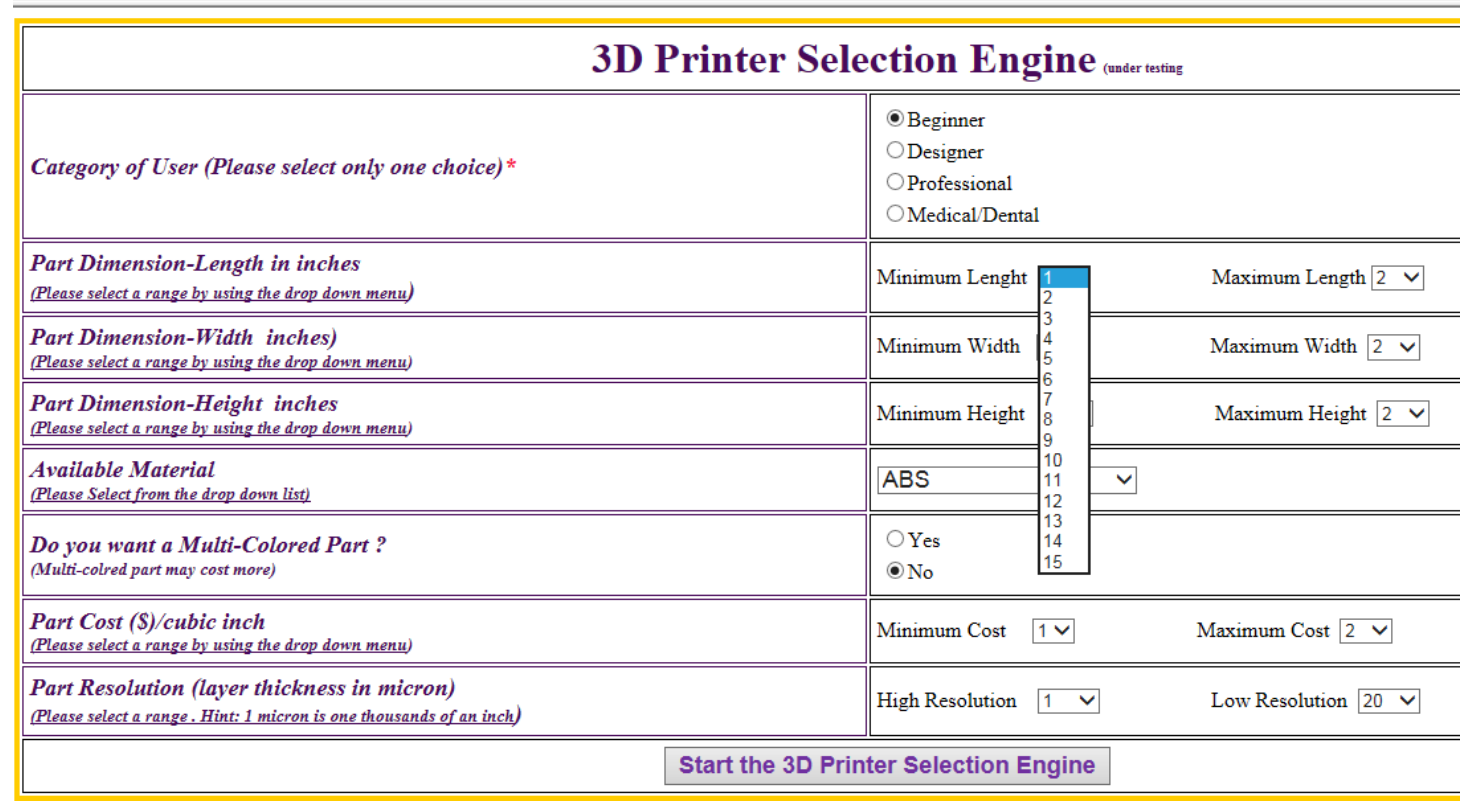

Figure 5. Selection Parameter-Drop Down Menu for Min. Part Length.

The users will have the ability to select the product's material using a drop down menu as depicted in Figure 6. Choice of part color is entered by means of a radio button. Range of part costs such as cost/cubic inch and resolution is entered through a drop down menus. 
Once the user completes and submits the selection engine form, the engine converts the users' inputs into matching and mapping query to a 3D printer database and a webpage containing suitable 3D printers are displayed as depicted in Figure 7.

\begin{tabular}{|c|c|c|c|}
\hline \multicolumn{4}{|c|}{ 3D Printer Selection Engine (under testing } \\
\hline \multicolumn{2}{|l|}{ Category of User (Please select only one choice)* } & \multicolumn{2}{|l|}{$\begin{array}{l}\text { Beginner } \\
\text { Designer } \\
\text { Professional } \\
\text { Medical/Dental }\end{array}$} \\
\hline \multicolumn{2}{|l|}{$\begin{array}{l}\text { Part Dimension-Length in inches } \\
\text { (Please select a range by using the drop down menu) }\end{array}$} & \multicolumn{2}{|l|}{ Minimum Lenght $1 \mathrm{~V}$} \\
\hline \multicolumn{2}{|l|}{$\begin{array}{l}\text { Part Dimension-Width inches) } \\
\text { (Please select a range by using the drop down menu) }\end{array}$} & \multicolumn{2}{|l|}{ Minimum Width $1 \mathrm{~V}$} \\
\hline \multicolumn{2}{|l|}{$\begin{array}{l}\text { Part Dimension-Height inches } \\
\text { Please select a range by using the drop down menu) }\end{array}$} & \multirow{7}{*}{$\begin{array}{l}\text { ABS } \\
\text { PLA } \\
\text { ABS,PLA } \\
\text { Nylon } \\
\text { ABS,Nylon } \\
\text { PLA,Nylon } \\
\text { Multi-material } \\
\text { Dental Material } \\
\text { Resin } \\
\text { Metal-Alloys } \\
\text { Metal-Steel } \\
\text { Metal-Titanium } \\
\text { Food } \\
\text { Cermaic } \\
\text { Carbon fibre } \\
\text { Bio Materials } \\
\text { ABS,PLA,Nylon } \\
\text { WAX and Resin Hybrid } \\
\end{array}$} & Maximum Height $2 \checkmark$ \\
\hline \multicolumn{2}{|l|}{$\begin{array}{l}\text { Available Material } \\
\text { (Please Select from the drop down list) }\end{array}$} & & \\
\hline \multicolumn{2}{|l|}{$\begin{array}{l}\text { Do you want a Multi-Colored Part? } \\
\text { (Multi-colred part may cost more) }\end{array}$} & & \\
\hline \multicolumn{2}{|l|}{$\begin{array}{l}\text { Part Cost }(\text { (S)/cubic inch } \\
\text { (Please select a range by using the drop down menu) }\end{array}$} & & Maximum Cost $2 \checkmark$ \\
\hline \multicolumn{2}{|l|}{$\begin{array}{l}\text { Part Resolution (layer thickness in micron) } \\
\text { (Please select a range. Hint: } 1 \text { micron is one thousands of an inch) }\end{array}$} & & Low Resolution $20 \mathrm{~V}$ \\
\hline \multirow{2}{*}{\multicolumn{2}{|c|}{ Start the 3D Print }} & & \\
\hline & & & \\
\hline
\end{tabular}

Figure 6. Selection Parameter-Drop Down Menu for Part Material

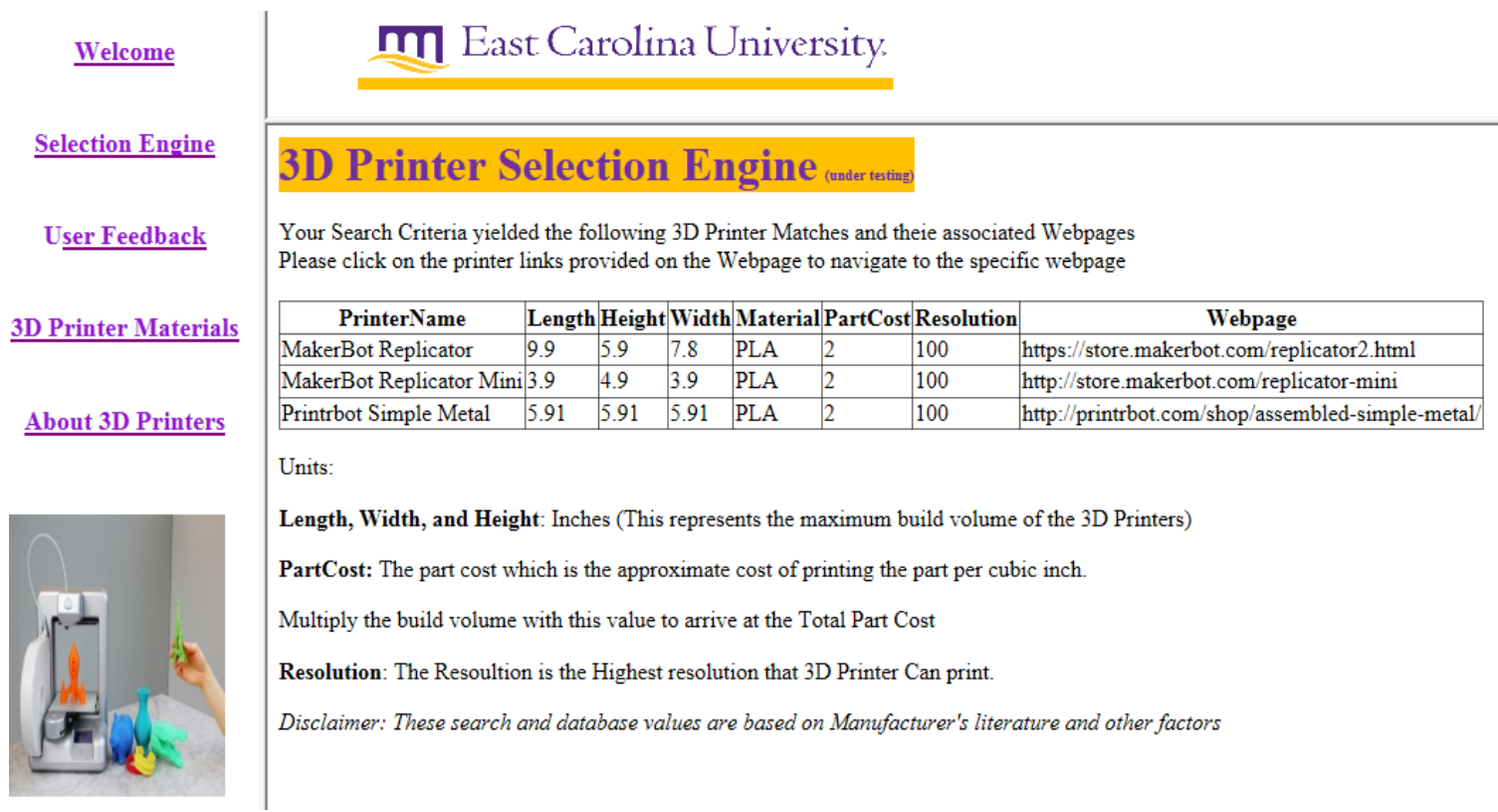

Figure 7. 3D Printer Match-Results Webpage. 
The 3D printer name, maximum build volume, material, part cost, resolution, and a link to the 3D printer Webpage is displayed. The users can copy the hyperlinks to a web browser to directly go the 3D Printer manufacturer's webpage.

Through the hyperlink user feedback, user is prompted to complete a quick survey summarizing their experiences with using the system. In addition they are asked for their thoughts on how to improve the system. The feedback will be used to improve the system. The feedback page is depicted in Figure 8.

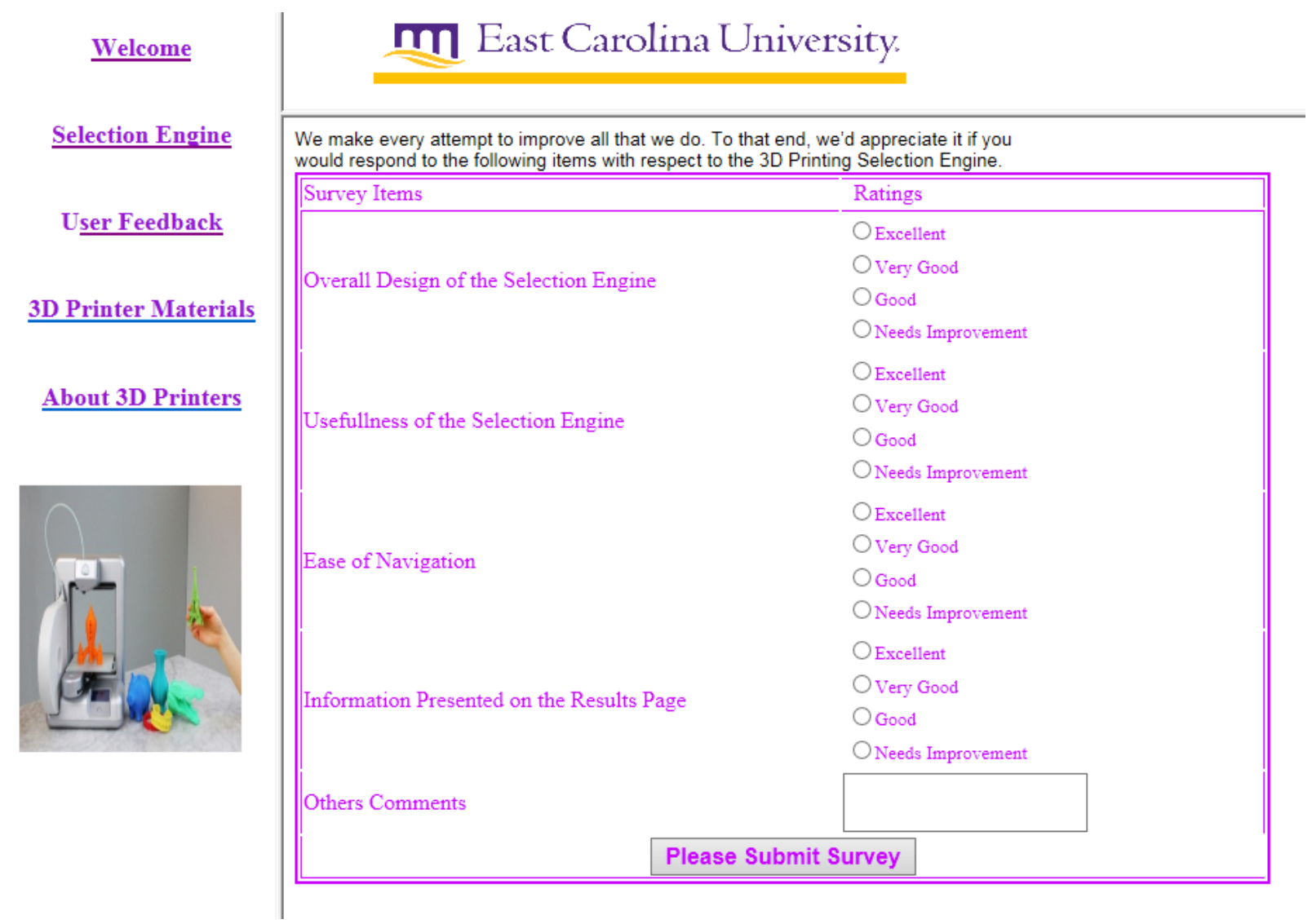

Figure 8. Selection Engine User Feedback Survey.

Hyper Links are also provided to educate novice users about 3D printers and materials as depicted in Figures 9 and 10. 


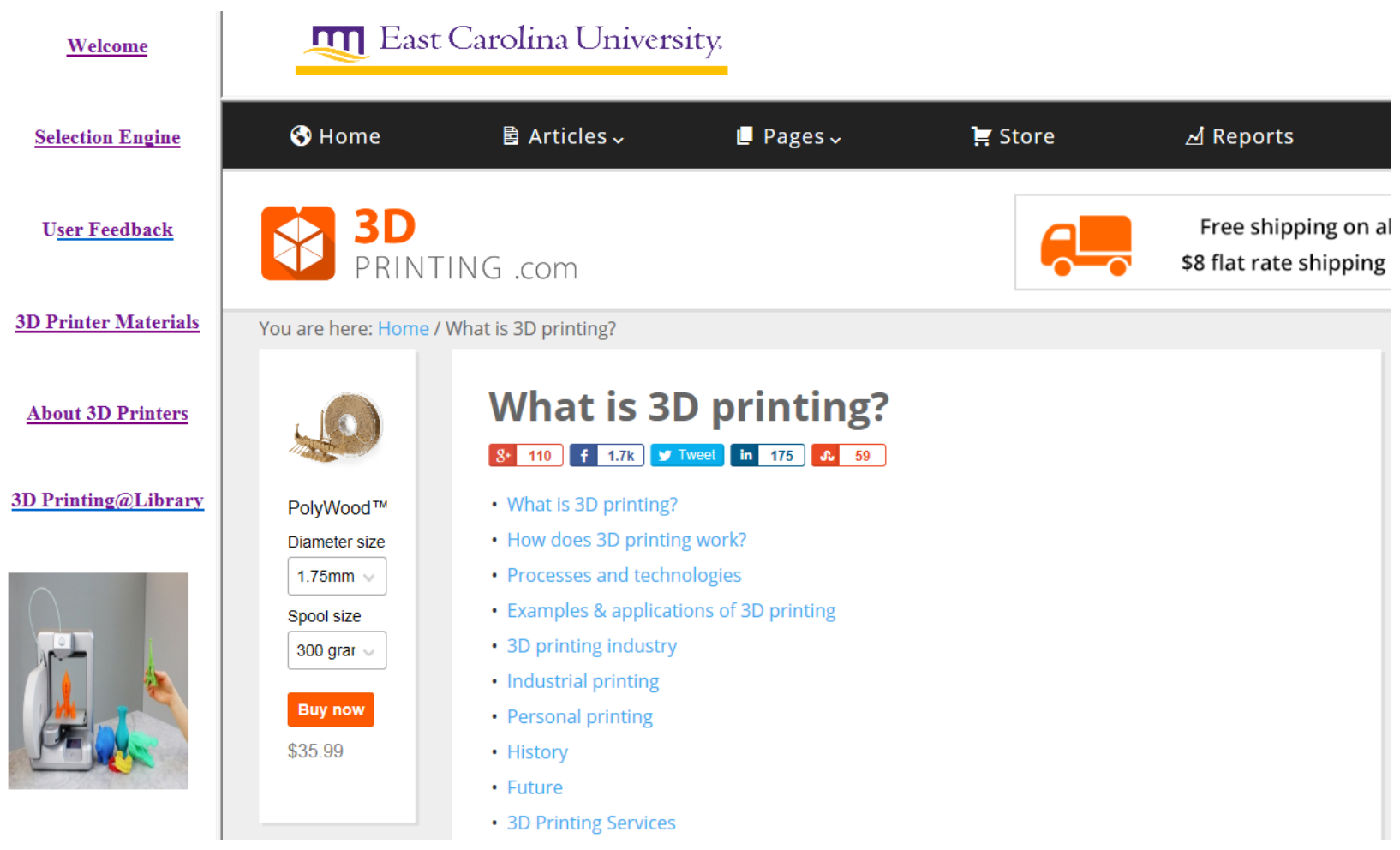

Figure 9. Hyperlink to educate Users on 3D Printers.

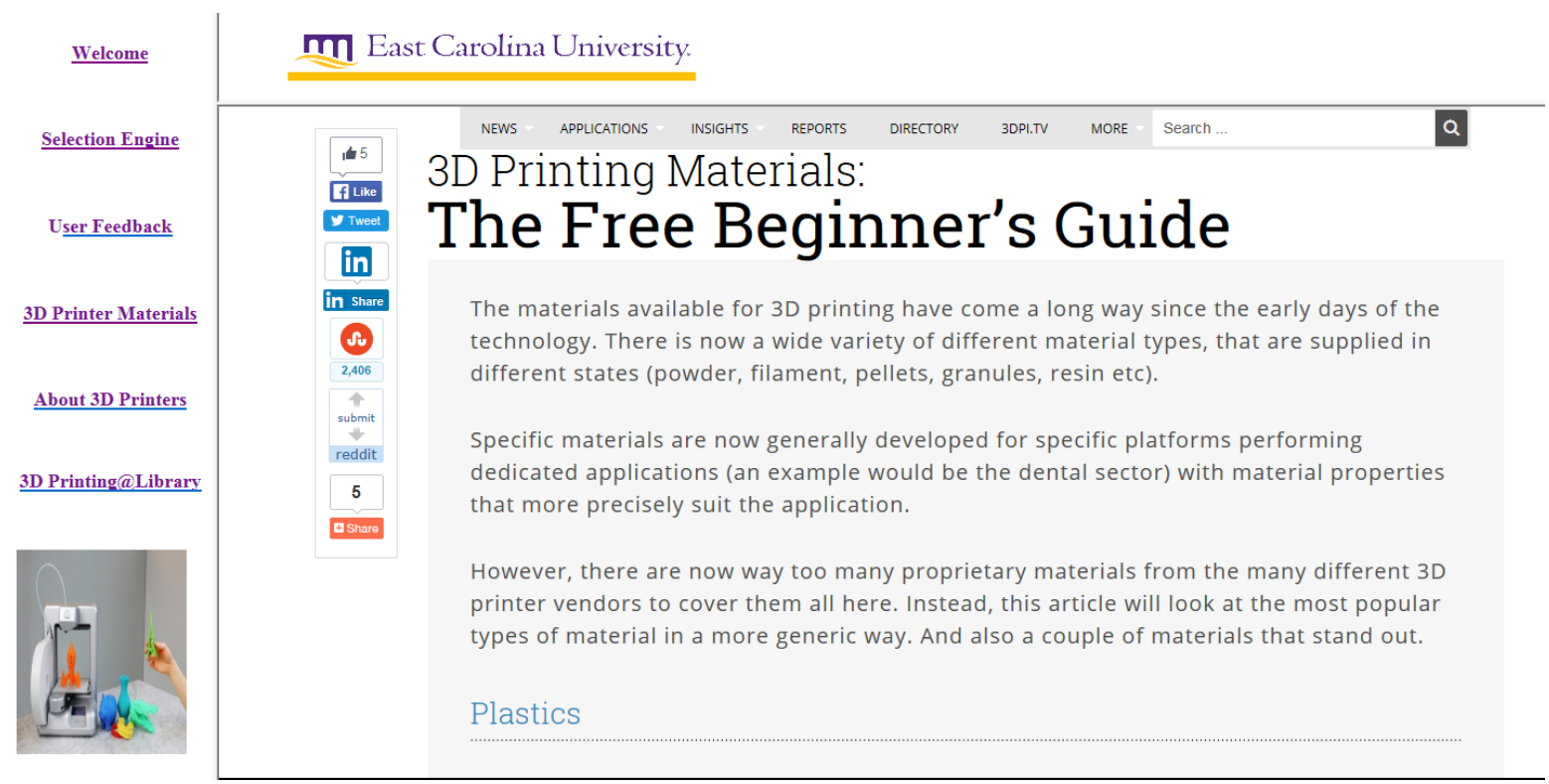

Figure 10. Hyperlink to educate Users on 3D Printing Materials. 


\section{System Design}

The selection system is designed and hosted on Microsoft Expression Web 4.0. The logo of the software is depicted in Figure $11{ }^{17}$. According to Microsoft, "Expression Web 4 gives you the tools you need to produce high-quality, standards-based Web sites: built-in support for today's Web standards, sophisticated CSS design capabilities and visual diagnostic tools".

All the webpages are designed using Active Server Pages (ASP). According to Microsoft ${ }^{17}$, "ASP.NET web pages enable you to create dynamic content for your site. With a static HTML page (.htm or .html file), the server fulfills a web request by reading the file and sending it as-is to the browser".

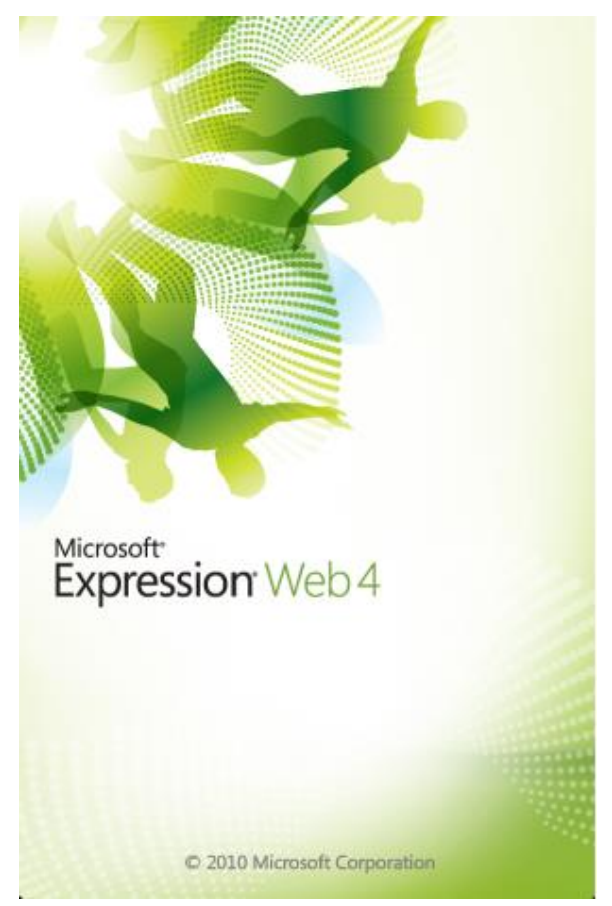

Figure 11. Microsoft Expression Web 4.0 Logo.

Once the user enters the desired product specifications and submits them to the 3D printer server, a Microsoft Access data source establishes a connection between the selection engine and the 3D printer Database. The 3D printer result and display webpage is designed to display results based on the connection to an Access Data source is displayed in Figure 12 and the Access database is depicted in Figure 13. According to Techopedia ${ }^{18}$, "A data source, in the context of computer science and computer applications, is the location where data that is being used come from. In a database management system, the primary data source is the database, which can be located in a disk or a remote server. The data source for a computer program can be a file, a data sheet, a spreadsheet, an XML file or even hard-coded data within the program". 


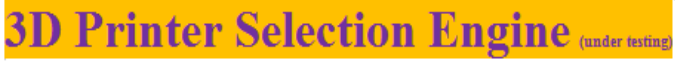

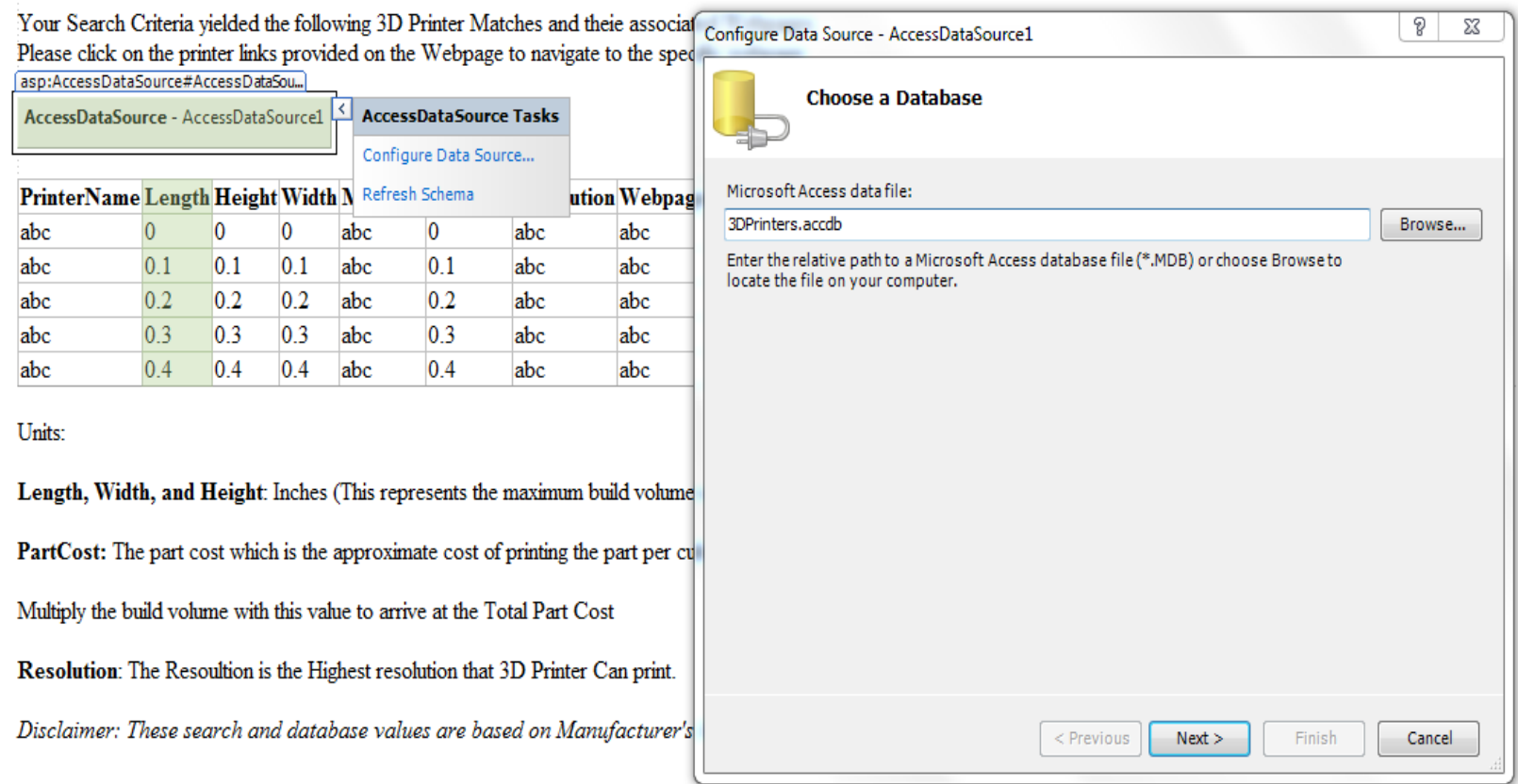

Figure 12. 3D Printer Result Webpage As Connected To Access Data Source.

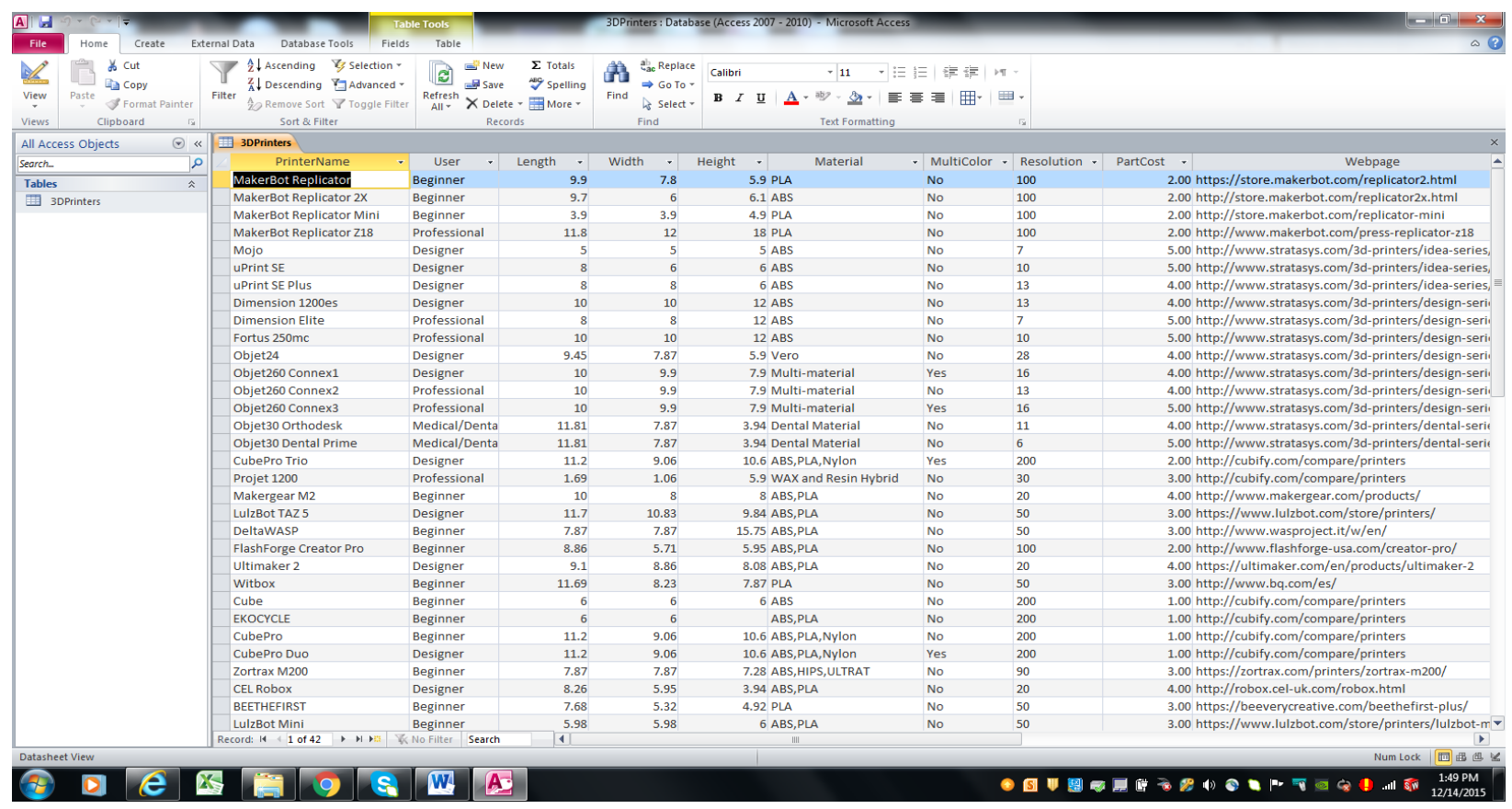

Figure 13. 3D Printer Access Database. 
The data source connecting the selection parameters to the 3D printer generates the results based on a programmed sequential query language (SQL) statement to the $3 \mathrm{D}$ printer database. According to Techopedia ${ }^{19}$, "Structured Query Language (SQL) is a standard computer language for relational database management and data manipulation. SQL is used to query, insert, update and modify data”. Figure 14 depicts the SQL Code programmed by the authors. The parameter placeholders depicted by "?" in this code are based on the user input in the selection form.

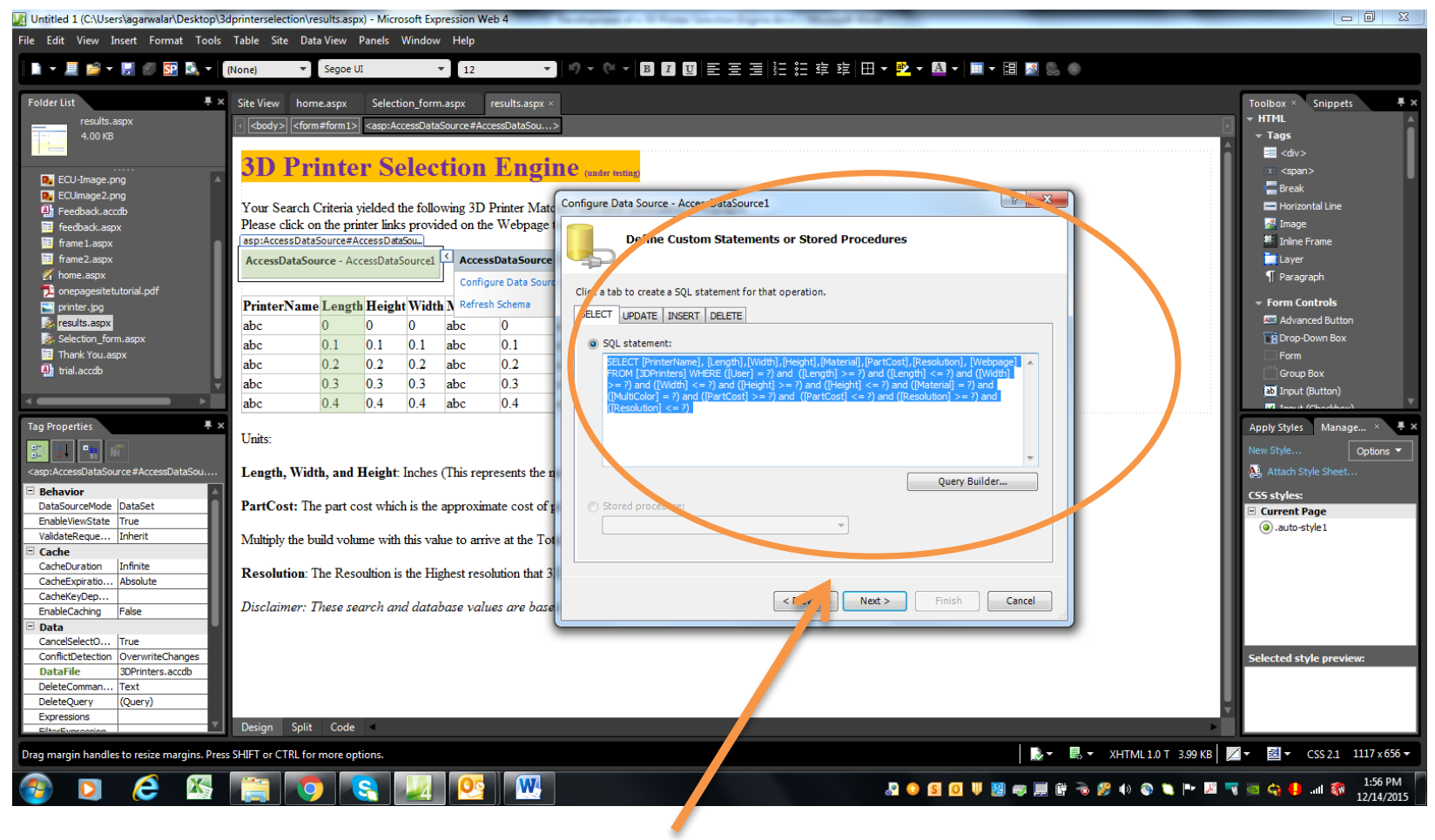

SELECT [PrinterName], [Length],[Width],[Height],[Material],[PartCost],[Resolution], [Webpage] FROM [3DPrinters] WHERE ([User] = ?) and ([Length] >= ?) and ([Length] $<=$ ?) and ([Width] $>=$ ?) and ([Width] $<=$ ?) and ([Height] $>=$ ?) and ([Height] $<=$ ?) and $([$ Material $]=$ ? $)$ and $([$ MultiColor $]=$ ?) and $([$ PartCost $]>=?)$ and $([$ PartCost $]<=$ ?) and ([Resolution] $>=$ ?) and ([Resolution $]<=$ ?)

Figure 14. SQL Code for the Selection Engine.

\section{Conclusions}

This paper focused on the deployment of a 3D Printer selection system. Many big 3D printer manufacturing companies provide their printer specifications in disparate format making an "apples to apples" comparisons difficult. The purpose of the selection system is to display printer specification in a common format so users are able to make appropriate comparisons. The technology, techniques and methods of designing the 3D printer selection engine was reported in this paper. The system, along with the website interface will be hosted on the webpage of an academic library during summer 2016. Once the webpage is hosted, the numbers of visitors using this webpage will be tracked. The authors will continuously expand and improve the 3D printing pairing engine. It is anticipated that users can save time by using the $3 \mathrm{D}$ printer 
selection webpage instead of visiting the hundreds of 3D printer manufacturers' webpages available to match their design requirements with an appropriate $3 \mathrm{D}$ printer.

\section{Acknowledgements}

The authors wish to thank Ms. Abigail Sweet Graves, Mr. Kevin Johnson, and Mr. Jack Ward for their assistance in compiling the data for the 3D printer database and in preparing this manuscript

\section{References}

1. Agarwala, R., \& Chin, R. A. (2016). Bridging the divide between users and 3D printers, 70th EDGD Midyear Conference, January 24-26, 2016, Daytona Beach, FL.

2. Matias, E., \& Rao, B. (2015). 3D printing: On its historical evolution and the implications for business. In Management of Engineering and Technology (PICMET), 2015 Portland International Conference on (pp. 551-558). IEEE.

3. Savini, A., \& Savini, G. G. (2015) A short history of 3D printing, a technological revolution just started. In History of High-Technologies and their Socio-Cultural Contexts Conference (HISTELCON), 2015 ICOHTEC/IEEE International (pp. 1-8). IEEE.

4. Reeves, P., \& Mendis, D. (2015). The Current Status and Impact of 3D Printing Within the Industrial Sector: An Analysis of Six Case Studies.

5. Kulkarni, A., \& Bhargava, M. R. (2015). 3D Printing. International Journal of Innovations \& Advancement in Computer Science, ISSN 2347 - 8616

6. Friedman, T. L. (2000). The Lexus and the Olive Tree. New York: Anchor Books.

7. Berman, B. (2012). 3-D printing: The new industrial revolution. Business horizons, 55(2), 155-162.

8. Stratasys Connex 3: http://www.stratasys.com/3d-printers/production-series/connex2-systems

9. Makerbot Printer Comparisons. Retrieved from http://store.makerbot.com/compare

10. 3D Systems: http://www.3dsystems.com/

11. Roberson, D. A., Espalin, D., \& Wicker, R. B. (2013). 3D printer selection: A decision-making evaluation and ranking model. Virtual and Physical Prototyping, 8(3), 201-212.

12. Wong, K. V., \& Hernandez, A. (2012). A review of additive manufacturing. ISRN Mechanical Engineering, 2012.

13. Rao, R. V., \& Padmanabhan, K. K. (2007). Rapid prototyping process selection using graph theory and matrix approach. Journal of Materials Processing Technology, 194(1), 81-88.

14. Mahesh, M., Wong, Y. S., Fuh, J. Y. H., \& Loh, H. T. (2004). Benchmarking for comparative evaluation of RP systems and processes. Rapid Prototyping Journal, 10(2), 123-135.

15. Masood, S. H., \& Soo, A. (2002). A rule based expert system for rapid prototyping system selection. Robotics and Computer-Integrated Manufacturing, 18(3), 267-274.

16. Brown, R., \& Stier, K. W. (2002). Selecting rapid prototyping systems. Journal of Industrial Technology, 18(1), 2.

17. Microsoft Expression Web 4.0: https://www.microsoft.com/expression/eng/

18. Techopedia-Data source: https://www.techopedia.com/definition/30323/data-source

19. Techopedia-Sequential Query Language (SQL): https://www.techopedia.com/definition/1245/structured-querylanguage-sql 